International Journal of Electrical Engineering and Technology (IJEET)

Volume 11, Issue 4, June 2020, pp. 191-203, Article ID: IJEET_11_04_022

Available online at https://iaeme.com/Home/issue/IJEET?Volume $=11 \&$ Issue $=4$

ISSN Print: 0976-6545 and ISSN Online: 0976-6553

DOI: https://doi.org/10.34218/IJEET.11.4.2020.022

\title{
VISUALIZING ROAD DAMAGE BY MONITORING SYSTEM IN CLOUD
}

\author{
Deepa D, R. Vignesh, Sivasangari A, Suja Cherukullapurath Mana, \\ B. Keerthi Samhitha and Jithina Jose \\ Assistant Professor, Department of Computer Science Engineering, \\ Sathyabama Institute of Science and Technology, Chennai, Tamilnadu, India
}

\begin{abstract}
Cloud computing gives many beneficial services to share large scale of information, storage resources, computing resources, and provide knowledge for research. In this paper, I have proposed the methodology for visualizing the road damage condition by monitoring and detecting the road damage and specifying the location of the damage by which others can prevent from accident response. In the proposed system is about the visualizing road damages using cloud database. That is we need some prevention by monitoring 'road damage' using mobiles. To find the road damage, the roads are monitored and the snapshots are taken. The snapshot images are then processed in the application developed without internet. The information details about the road damage will be sent to the cloud. Then the cloud stores that information in the database. This information is very helpful in visualizing road damage locations to the users. Different maps are developed for different kinds of users based on the above gathered information. There are three types of users involved. They are Vehicle Users, Corporation Users and Administration Users. The Vehicle user gets the visualized map of the specified road damage on the path between the source and destination. The Corporation user visualizes the road map for damaged locations in a specified area. The Administration user visualizes the map of the Client broker locations in a specified area.
\end{abstract}

Key words: Cloud database, Client Broker, Visualizing, Cloud Computing, Road Damage

Cite this Article: Deepa D, R. Vignesh, Sivasangari A, Suja Cherukullapurath Mana, B. Keerthi Samhitha and Jithina Jose, Visualizing Road Damage by Monitoring System in Cloud. International Journal of Electrical Engineering and Technology, 11(4), 2020, pp. 191-203.

https://iaeme.com/Home/issue/IJEET?Volume $=11 \&$ Issue $=4$

\section{INTRODUCTION}

Cloud computing can provide resource as services via virtualization technology which provides software environment in the form of virtual machine VM. In cloud computing, applications with operating system, specific hardware, software, and libraries requirements 
can be executed in a larger amount of resources by instantiating VMs from a repository so that requirements can be supported. The detection of road damages and their correct locations contributes to the improvement of driver safety and ensures safe driving by visualizing the map for the road damage specification. Road damage assessment has been identified as a critical issue related to the possibility of making the transportation system more safe, efficient and comfortable. This would enable them to take preventive measures before further damage occurs. It is worth noting damaged roads with several damages which can lead to traffic choking and cause accidents.

In such a scenario, we need some prevention by monitoring ,road damage using mobiles. To find the road damage, the roads are monitored and the snapshots are taken. The snapshot images are then processed in the application developed without internet usage. The information such as the latitude, longitude and amount of the damage of the road damage are gathered from the images. The information gathered will be sent to the appropriate client broker who in turn sends the gathered information to the cloud. Then the cloud stores that information in the database.

This information is very helpful in visualizing road damage locations to the users. Different maps are developed for different kinds of users based on the above gathered information. There are three types of users involved. They are Vehicle Users, Corporation Users and Administration Users. The Vehicle user gets the visualized map of the specified road damage on the path between the source and destination. The Corporation user visualizes the road map for damaged locations in a specified area. The Administration user visualizes the map of the Client broker locations in a specified area. Visualization is the creation of a virtual version of something such as an operating system, a server, a storage device or network resources. Scheduling the basic processing units on a computing environment has always been an important issue. In cloud computing, a user may require a set of virtual machine cooperating with each other to accomplish one task. [3]

\section{RELATED WORK}

This section lists out the various research works related to the problem that we have considered and the features and the drawbacks of such approaches.

[9] Described how each road surface is obtained and used for rough discrimination between road and road points. Road points are grouped based on vicinity and false areas are rejected. Each road area is classified into obstacles or traffic road patches for path planning by using criteria related to the density of the $3 \mathrm{D}$ points. The proposed real-time algorithm was evaluated in an urban scenario and can be used in complex applications, from ego-pose estimation to path planning. Further work to be done includes how using the tracking can greatly improve the robustness of the method, MMXSSE processor features can reduce the processing time to half, and enhancing the algorithm to cope better with various types of noise in the 3D dataset.

[8] Proposed approach removes the need for global matching performance by the vision front-end and instead it must only pick the best match within any short sequence of images. This approach is applicable over environment changes that render traditional feature-based techniques ineffective. Using two car-mounted camera datasets they demonstrate the effectiveness of the algorithm and compare it to one of the most successful feature-based SLAM algorithms, FAB-MAP.

[10] Discussed the key features of the road shape is a key element for driver assistance systems which support the driver in complex scenarios like construction sites. The paper presents an approach to estimate road boundaries based on static objects bounding the road. A map based environment description and an interpretation algorithm identifying the road 
boundaries in the map are used. Two approaches are presented for estimating the map, one based on a radar sensor, one on a mono video camera. The estimated boundaries are independent of road markings and as such can be used as orthogonal information with respect to detected markings. Results of practical tests using the estimated road boundaries for a lane keeping system are presented.

[5] Ensure that each mobile device consumes the same proportion of its energy to its energy capacity while meeting its user SLA requirement; an energy cost model is used to model the cost of executing a task in different computing facilities including mobile devices, the local cloudlet, and the remote cloud. They then devise an efficient online algorithm for fairly offloading location-aware tasks among mobile users. Even though they finally conduct experiments by simulations to evaluate the performance of the proposed algorithm, the issues are that mobile users do not have the knowledge about offload in without use of internet, when they have tasks to be offloaded in the future.

\section{PROPOSED MONITORING SYSTEM FOR VISUALIZING THE ROAD DAMAGE}

The proposed frame work consists of the following modules as follows:

Step 1: Vehicle User Module: The vehicle user requests the cloud for a specific route about road damage information. The route name is decoded using Polyline decode algorithm in the Google map API. This will convert the string name into corresponding latitude and longitude. Each request is processed in the cloud and the requested routes are returned as plotted in the Map.

Input : Source and Destination

Output: Map of specified path plotted with road damages

Methodology: Polyline decode

Procedure:

- Request Google Map API data

- Source and Destination address is entered as string.

- The polyline decode converts the string into latitude and longitude values and plotted the multiple path in Google Map with source and destination.

- Between the source and destination address, polyline is plotted in blue color.

- Get the source and destination data stored in cloud.

Step 2: Corporation User Module: The corporation user requests the road damage information for a specific distance to the cloud. The cloud responds to the user by returning the road damage points stored for the requested distance. The damage points are plotted in the map to facilitate the corporation users.

Input : Distance specification

Output: Road map for damaged location in an area specified

Methodology: Haversine Method

Procedure:

- Request Google Map API data.

- Corporation user enters the specific distance to know the damage.

- Using Geolocation marker point, the distance specified is covered from the current location point and the road damaged points are retrieved. 
- Using Haversine Formula, Compute distances between source and destination on the surface of a sphere using the latitude and longitude of the two points and retrieve the damaged data from the cloud.

- Plot the damages in the corporation map.

Step 3: Administration User Module: The Administration user requests the cloud for a specific area, the cloud processes the request and returns the requested area as plotted map using client broker location markers in the map. The administration user grants the permission to remove damage points.

Input : Source and Destination

Output: Map of specified route plotted with client broker and road damages.

Procedure:

- Request Google Map API data.

- Get the source and the destination address and decode string to latitude and longitude values.

- Set the client brokers from source to destination in such a way that the gateways do not intersect each other.

- Retrieve the damage points from cloud between source and destination point.

- Administration user can update the damage points by removing the points which are repaired.

Step 4: Client Broker To Cloud Module: The client broker updates the cloud twice or thrice a day so that the updated information is placed in the cloud database.

Input : CSV file which contains the damage information

Output: Visualized Map of plotted damage

Procedure:

- Client broker sends the information about the damage point to cloud.

- The information contains latitude, longitude and amount of damage.

- The damage points are plotted in red color in the map.

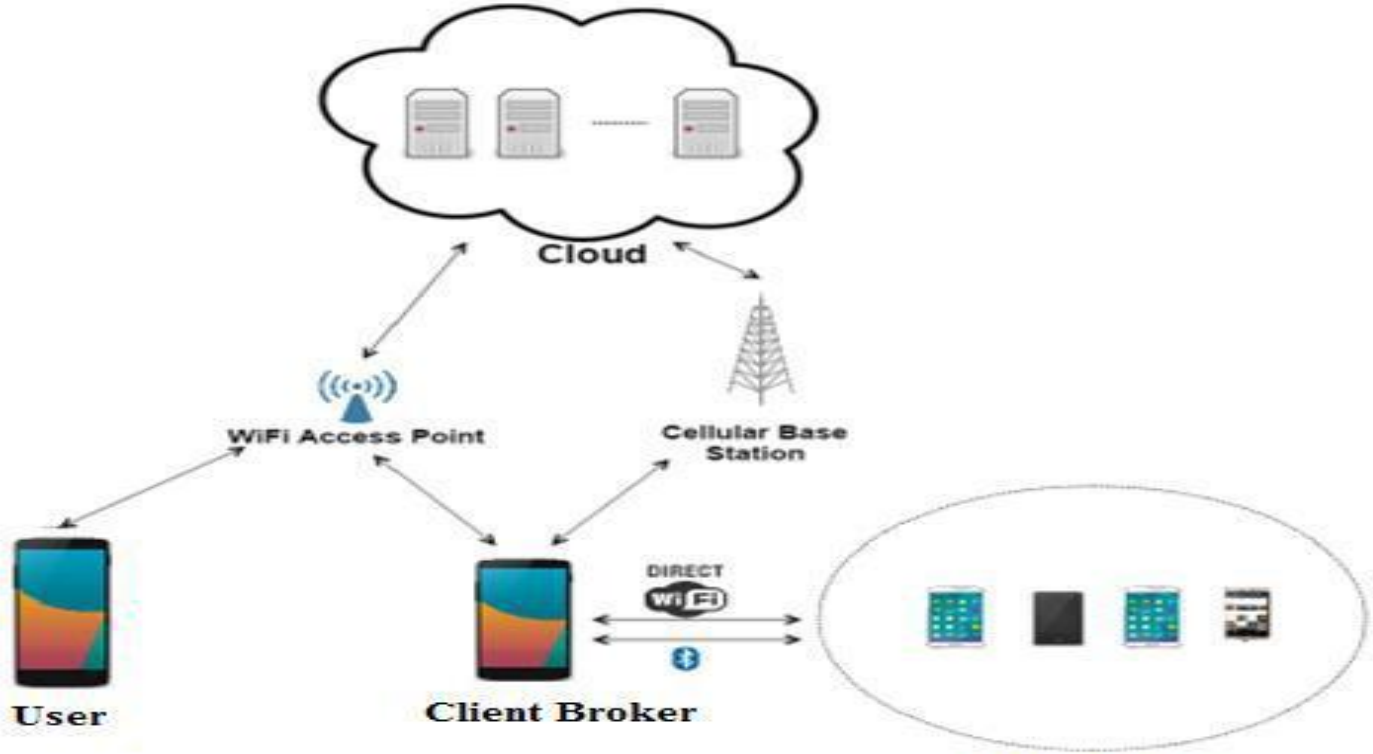

Mobile cloud

Figure 1 Overview of the proposed Vehicle Monitoring System 
The figure 1 shows the overall architecture of the proposed project. The architecture is divided into cloud service establishment and client broker process. Last phase work was done on the client broker process while this phase concentrates on the cloud service establishment. The cloud service establishment deals with the different kinds of users requesting different kinds of information to the cloud and getting the different types of visualized maps about the road damage.

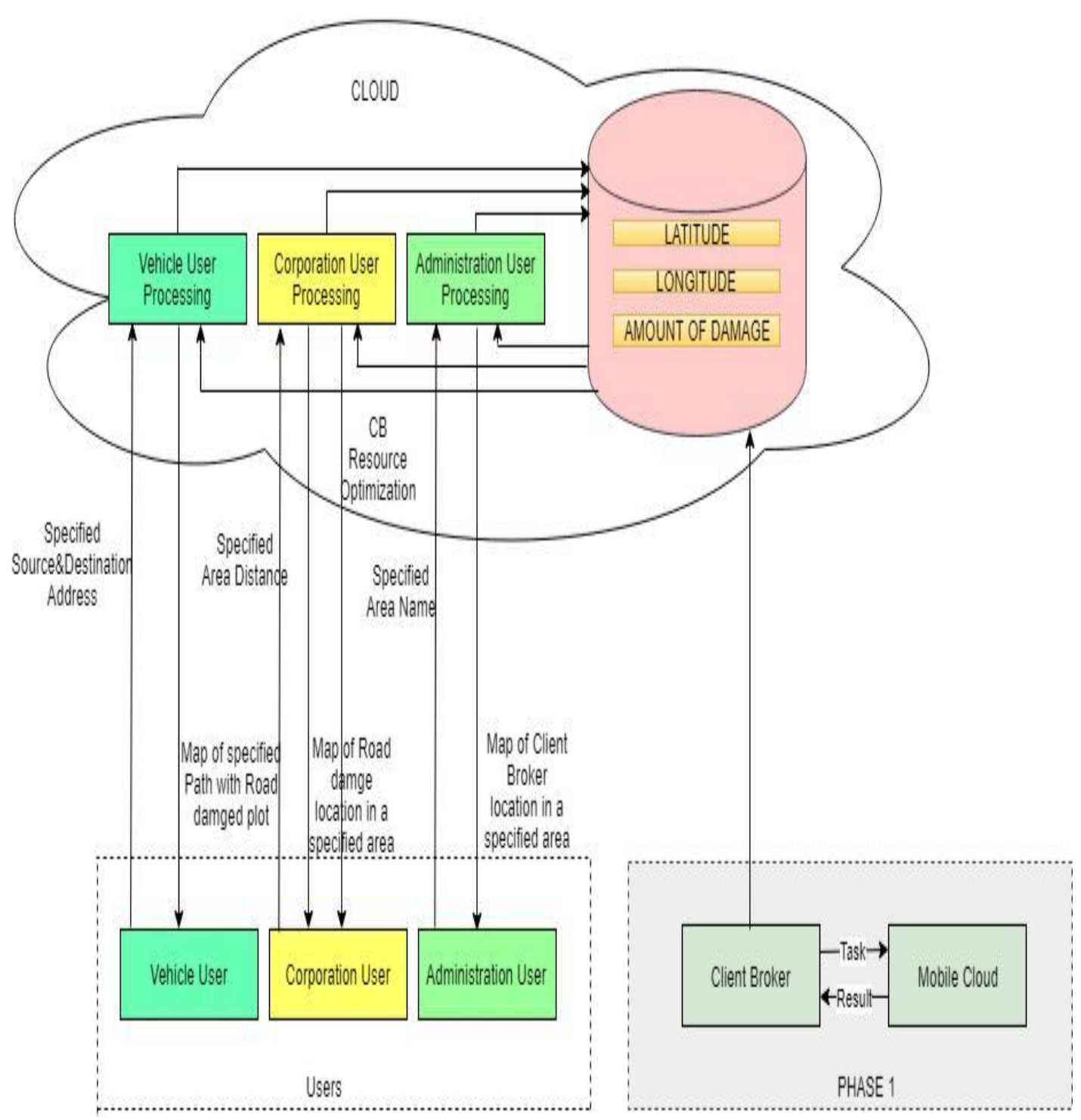

Figure 2 Detailed design of the Vehicle Monitoring System

Each and every mobile node sends the information about each road damaged area as latitude and longitude and the amount of the damage to a client broker. Client broker sends those results to the Cloud. The vehicle user sends a request to the cloud for a specific route. That route name is decoded by using Polyline decode algorithm in the Google map API. That will convert the string name into corresponding latitude and longitude. Then each request is processed in the cloud which returns the requested route as plotted in the Map. The Corporation user sends a request to the cloud for a specific area then it retrieves damaged points stored in the cloud which then returns the requested area as plotted damage points in the map. The Administration user sends a request to the cloud for a specific path name, which 
is processed and then returns the requested route as plotted client broker location markers and updates the damage in the map.

\section{EXPERIMENTS AND RESULTS}

\subsection{Dataset Description}

This dataset contains the data obtained from client broker processed information. The dataset is about the damage location details which include fields like LATITUDE, LONGITUDE, and AMOUNT_OF_DAMAGE. This information going to store in the cloud. After that based on the user requirements the details are extract from cloud.

Table 1 Road_damage dataset

\begin{tabular}{|c|c|c|}
\hline LATITUDE & LONGITUDE & AMOUNT_OF_DAMAGE \\
\hline 13.010236 & 80.215651 & 45 \\
\hline 13.015177 & 80.224846 & 60 \\
\hline 13.012459 & 80.226992 & 40 \\
\hline 13.010808 & 80.224288 & 50 \\
\hline 13.007902 & 80.233491 & 35 \\
\hline 12.931809 & 80.123201 & 44 \\
\hline 12.941011 & 80.133157 & 80 \\
\hline 12.949836 & 80.139016 & 40 \\
\hline 12.953195 & 80.141601 & 55 \\
\hline 12.965812 & 80.148436 & 45 \\
\hline 12.961233 & 80.145904 & 30 \\
\hline 12.956674 & 80.143457 & 55 \\
\hline 13.045447 & 80.113774 & 50 \\
\hline 13.043767 & 80.120824 & 55 \\
\hline 13.042407 & 80.124731 & 70 \\
\hline 13.041818 & 80.125889 & 50 \\
\hline 13.041519 & 80.126542 & 45 \\
\hline 13.038461 & 80.267249 & 45 \\
\hline 13.042475 & 80.267674 & 55 \\
\hline 13.043931 & 80.266397 & 35 \\
\hline 13.053622 & 80.263915 & 40 \\
\hline 13.054291 & 80.264151 & 60 \\
\hline 13.048433 & 80.265509 & 60 \\
\hline 13.033889 & 80.277394 & 30 \\
\hline
\end{tabular}

\subsection{Implementation Results}

This section explains the experimental results obtained on executing the proposed system.

\subsubsection{Vehicle User Module}

The vehicle user gets the visualized map of the specified road damage path between the source and destination.

The vehicle user requests the cloud for a specific route about road damage information. The route name is decoded using Polyline decode and it converts the string name into corresponding latitude and longitude. Each request is processed in the cloud and the requested routes are returned as plotted in the Map. 
Deepa D, R. Vignesh, Sivasangari A, Suja Cherukullapurath Mana, B. Keerthi Samhitha and Jithina Jose

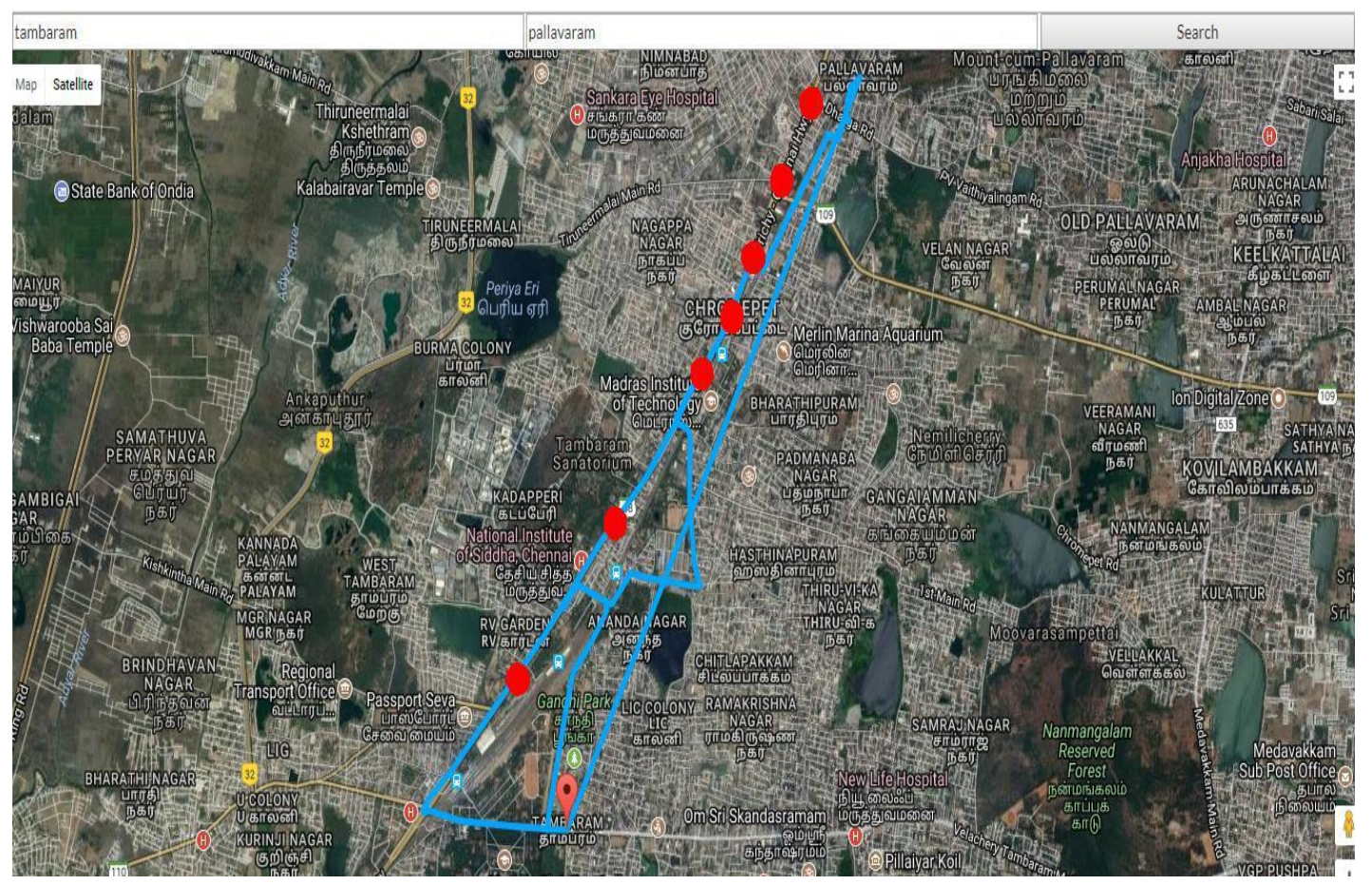

Figure 3 Map for a Vehicle User

\subsubsection{Administration User Module}

The administration user gets the visualized map of the specified road damage path and the client brokers are plotted along with the damages.

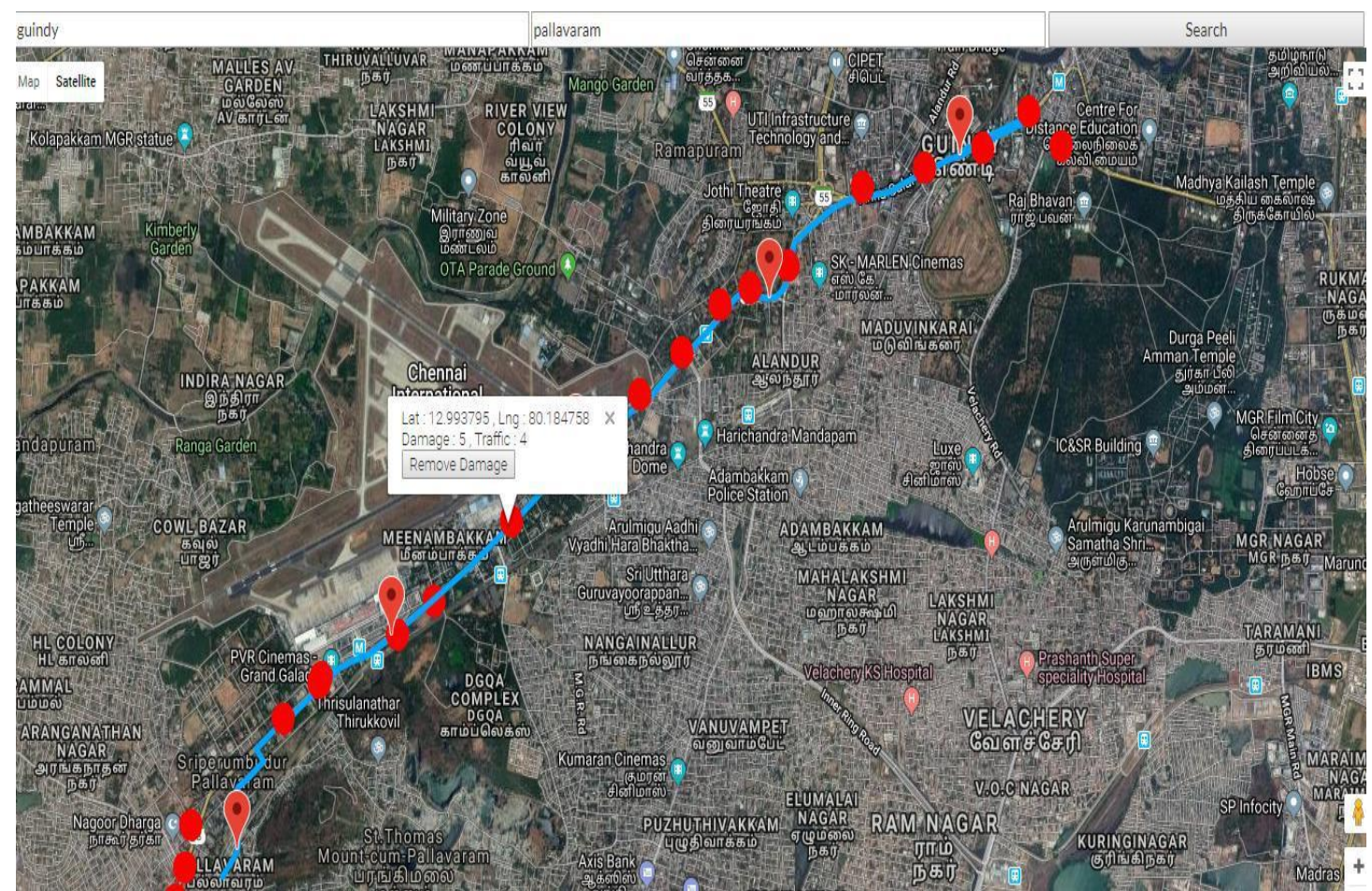

Figure 4 Map for Administration User

The Administration user requests the cloud for a specific area; the cloud processes the requests and returns the requested area as plotted map using client broker location markers in the map. The administration user only has the permission to remove the damage points. 


\subsubsection{Corporation User Module}

The corporation user gets the visualized map of the specific distance of road damage locations.

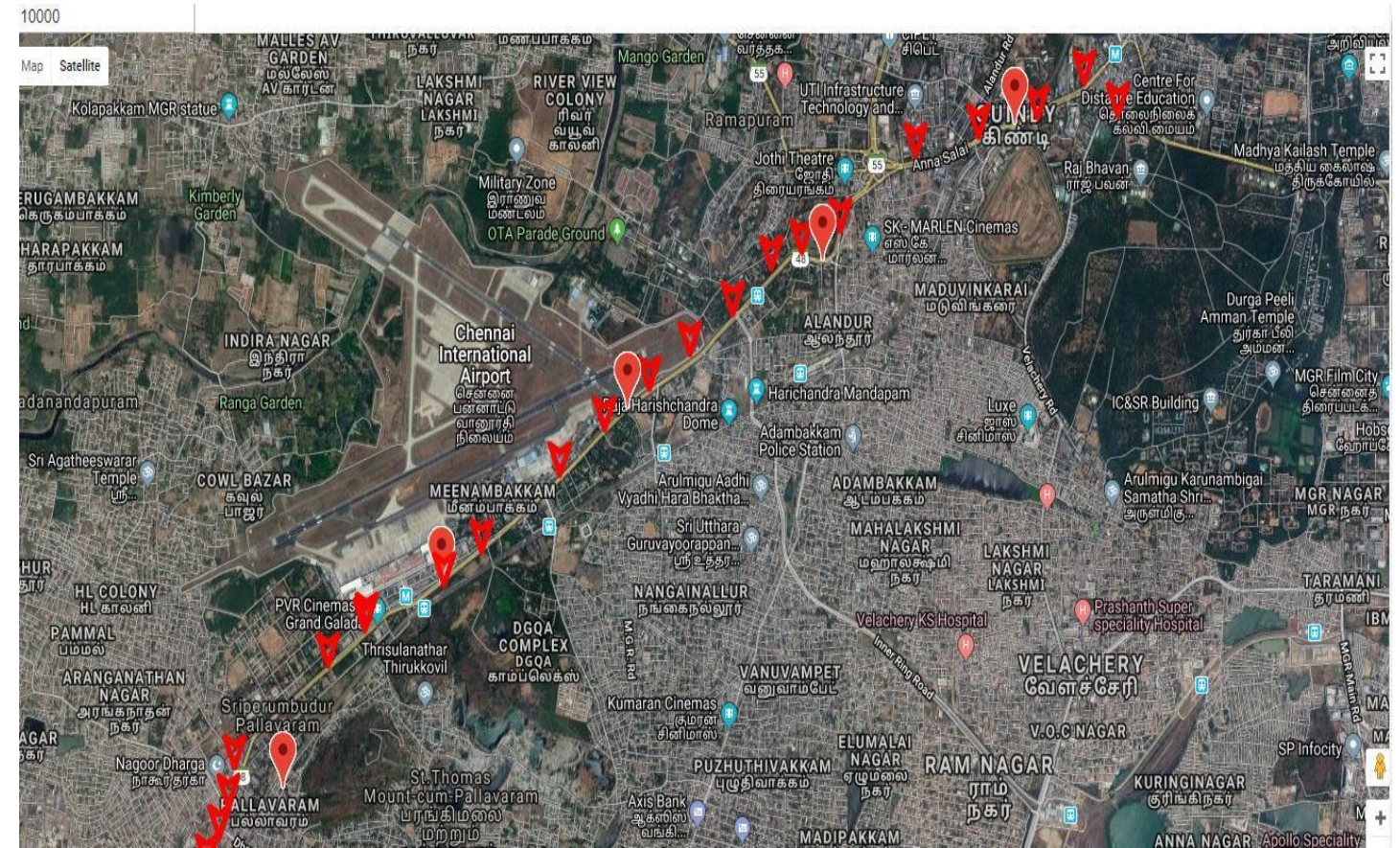

Figure 5 Map for Corporation User

The corporation user requests the road damage information for a specific distance to the cloud. The cloud responds to the user by returning the road damage points stored for the requested distance. The damage points are plotted in the map to facilitate the corporation users.

\subsubsection{Client Broker to Cloud Processing Input}

The client broker has the gathered information about the road damage, and It uploads this information to the cloud.

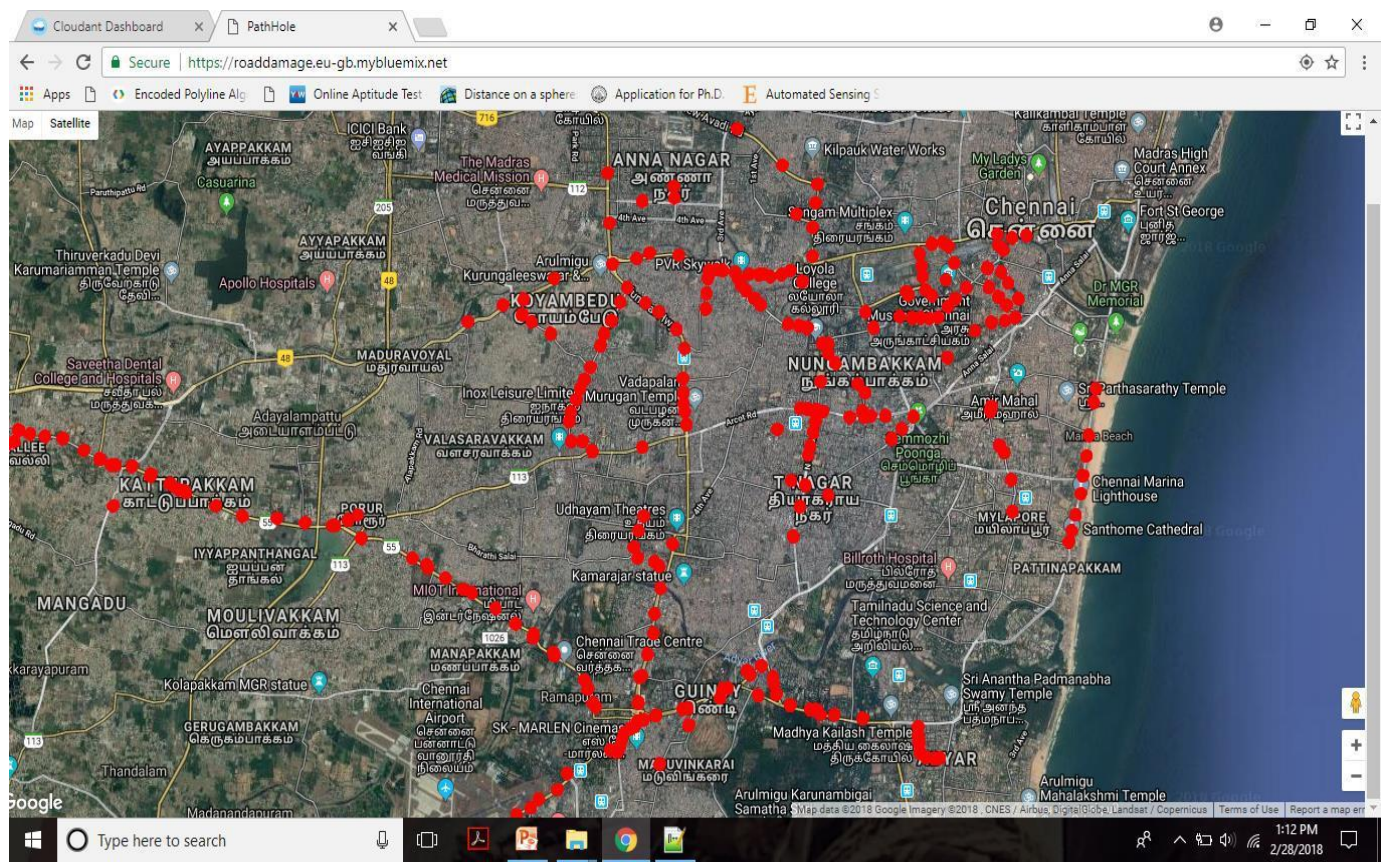

Figure 6 Map for Entire Damages 
Deepa D, R. Vignesh, Sivasangari A, Suja Cherukullapurath Mana, B. Keerthi Samhitha and Jithina Jose

\subsection{Evaluation Metrics}

In this section, the proposed system is evaluated based on Client Broker And the Resource Count allocated for each client broker.

Table 2 Resource Allocation Count

\begin{tabular}{|c|c|}
\hline Client Broker Number & Resource Allocation Count \\
\hline CB0 & 3 \\
\hline CB1 & 3 \\
\hline CB2 & 3 \\
\hline CB3 & 25 \\
\hline CB4 & 16 \\
\hline CB5 & 11 \\
\hline CB6 & 19 \\
\hline CB7 & 3 \\
\hline CB8 & 3 \\
\hline CB9 & 12 \\
\hline CB 10 & 3 \\
\hline CB11 & 3 \\
\hline CB12 & 21 \\
\hline CB13 & 19 \\
\hline CB14 & 3 \\
\hline CB15 & 4 \\
\hline CB16 & 26 \\
\hline CB17 & 26 \\
\hline CB18 & 26 \\
\hline CB19 & 26 \\
\hline CB20 & 11 \\
\hline
\end{tabular}

The evaluation is based on the Resource Allocation Count to each client broker. This is achieved by using PSO (Particle Swarm Optimization) technique. This is the best cloud resource optimization technique because this technique is useful for Small size data and also applicable for big size data. 
The below graph is generate for the 20 client brokers in $\mathrm{x}$-axis and in $\mathrm{y}$-axis for Resource Allocation Count to their corresponding client broker.

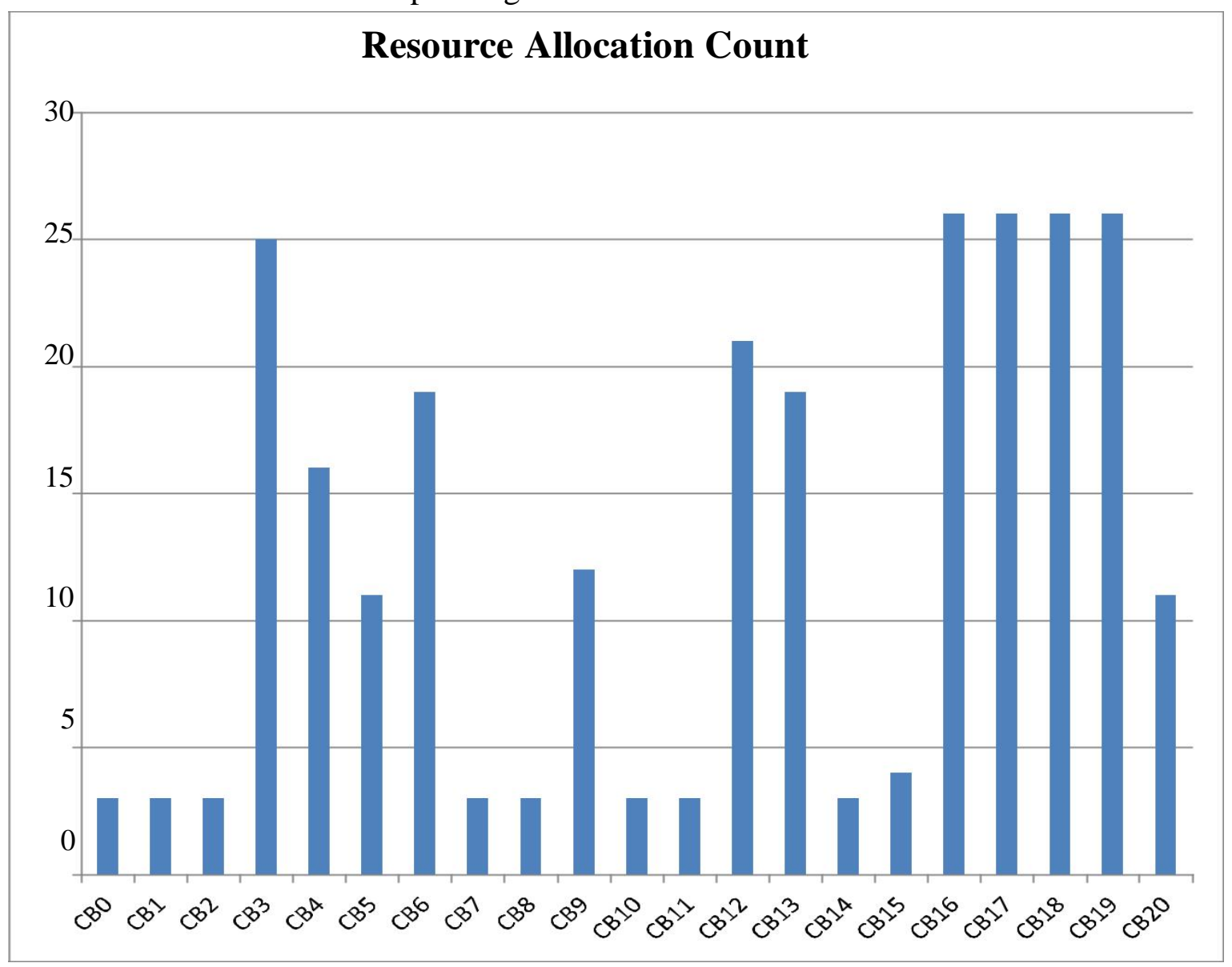

Figure 7 Graphs for Client Broker Resource Allocation Count

\subsection{Test Cases}

Table 3 Test Cases for the Proposed Vehicle Monitoring System

\begin{tabular}{|l|c|l|l|l|}
\hline \multicolumn{1}{|c|}{ Module Name } & Test No & \multicolumn{1}{|c|}{ Test Name } & \multicolumn{1}{|c|}{$\begin{array}{l}\text { Expected } \\
\text { Outcome }\end{array}$} & \multicolumn{1}{|c|}{ Actual Outcome } \\
\hline $\begin{array}{l}\text { CLIENT BROKER } \\
\text { TO CLOUD } \\
\text { MODULE }\end{array}$ & 1 (a) & $\begin{array}{l}\text { If input dataset } \\
\text { contains three } \\
\text { fields }\end{array}$ & $\begin{array}{l}\text { It will accept and } \\
\text { proceed with the } \\
\text { cloud access. }\end{array}$ & $\begin{array}{l}\text { It will accept and } \\
\text { proceed with the } \\
\text { cloud access. }\end{array}$ \\
\hline & 1 (b) & $\begin{array}{l}\text { If input dataset } \\
\text { contains more } \\
\text { than three } \\
\text { fields }\end{array}$ & $\begin{array}{l}\text { It will not accept } \\
\text { to access the } \\
\text { cloud process. }\end{array}$ & $\begin{array}{l}\text { It will not accept } \\
\text { to access the } \\
\text { cloud process. }\end{array}$ \\
\hline & 1 (c) & $\begin{array}{l}\text { If input dataset } \\
\text { contains less } \\
\text { than three } \\
\text { fields }\end{array}$ & $\begin{array}{l}\text { It will not accept } \\
\text { to access the } \\
\text { cloud process. }\end{array}$ & $\begin{array}{l}\text { It will not accept } \\
\text { to access the } \\
\text { cloud process. }\end{array}$ \\
\hline & 1(d) & $\begin{array}{l}\text { If input dataset } \\
\text { contains }\end{array}$ & $\begin{array}{l}\text { It will not accept } \\
\text { to access the }\end{array}$ & $\begin{array}{l}\text { It will not accept } \\
\text { to access the }\end{array}$ \\
\hline
\end{tabular}


Deepa D, R. Vignesh, Sivasangari A, Suja Cherukullapurath Mana, B. Keerthi Samhitha and Jithina Jose

\begin{tabular}{|c|c|c|c|c|}
\hline & & missing fields & cloud process. & |cloud process. \\
\hline \multirow[t]{3}{*}{\begin{tabular}{|l} 
VEHICLE USER \\
MODULE,CORPO \\
RATION USER \\
MODULE,ADMIN \\
ISTRATIO USER \\
MODULE
\end{tabular}} & 2 (a) & $\begin{array}{l}\text { If the dataset } \\
\text { contains the in } \\
\text { between points } \\
\text { of the source } \\
\text { and destination }\end{array}$ & $\begin{array}{l}\text { It allows } \\
\text { retrieving points } \\
\text { from cloud and } \\
\text { plotting the } \\
\text { points on the } \\
\text { polyline from } \\
\text { source and } \\
\text { destination. }\end{array}$ & $\begin{array}{l}\text { It allows } \\
\text { retrieving points } \\
\text { from cloud and } \\
\text { plotting the } \\
\text { points on the } \\
\text { polyline from } \\
\text { source and } \\
\text { destination. }\end{array}$ \\
\hline & 2(b) & If the dataset & It will not allow & It will not allow \\
\hline & & $\begin{array}{l}\text { does not } \\
\text { contains the in } \\
\text { between points } \\
\text { of the source } \\
\text { and destination }\end{array}$ & $\begin{array}{l}\text { retrieving points } \\
\text { from cloud. }\end{array}$ & $\begin{array}{l}\text { retrieving points } \\
\text { from cloud. }\end{array}$ \\
\hline \multirow[t]{2}{*}{$\begin{array}{l}\text { CLOUD } \\
\text { DATABASE }\end{array}$} & $3(\mathrm{a})$ & $\begin{array}{l}\text { If database } \\
\text { created and } \\
\text { connect with } \\
\text { the application }\end{array}$ & $\begin{array}{l}\text { The application } \\
\text { run correctly and } \\
\text { data are stored } \\
\text { and retrieve } \\
\text { properly }\end{array}$ & $\begin{array}{l}\text { The application } \\
\text { run correctly and } \\
\text { data are stored } \\
\text { and retrieve } \\
\text { properly }\end{array}$ \\
\hline & $3(\mathrm{~b})$ & $\begin{array}{l}\text { If database not } \\
\text { created }\end{array}$ & $\begin{array}{l}\text { The application } \\
\text { cannot retrieve } \\
\text { data. }\end{array}$ & $\begin{array}{l}\text { The application } \\
\text { cannot retrieve } \\
\text { data. }\end{array}$ \\
\hline
\end{tabular}

\section{CONCLUSION AND FUTURE WORK}

In the proposed system I used the cloud for Detecting and visualizing road damage monitoring. The proposed vehicle monitoring system was developed as an android application for detecting the road damage is developed. This application does image processing to detect damage in the road and specifies location. The client broker receives the damage information like latitude, longitude and amount of damage.

That is the data are stored in the cloud. Then the three users like Vehicle user can able to request to cloud to retrieve specific route road damage details and plotted in Google Map with the Polyline along plotted the damages in the specific route. Then the Corporation user request to cloud to retrieve specific distance of damage details and plotted damages in Google Map. Then the Administration user requests the cloud for a specific area, the cloud processes the request and returns the requested area as plotted map using client broker location markers in the map. The administration user grants the permission to remove damage points.

Though the accuracy is based on the road image intensity it may be exact accuracy using advance machine learning method used in the evaluation of damage to roads in Indonesia is PCI (Pavement Condition Index) method. PCI method is a method of road pavement condition assessment based on the type of damage, severity level and density of damages compare to the wide of road surfacing. Application of PCI method tend to be less desirable because of the classification of the type of damage and the level of severity measurements and density calculation are performed by manual observations at each segment and further calculation are still needed to get the index value. 


\section{LIST OF ABBREVIATIONS}

The following are the list of abbreviations used in this paper:

QOS - Quality Of Service

VM - Virtual Machine

VMM — Virtual Machine Monitor

VMP — Virtual Machine Placement

SLA - Service Level Agreement

\section{ACKNOWLEDGMENTS}

We are highly indebted to our respectable Chancellor, Dr. Mariazeena Johnson, B.E., MBA, M.Phil., Ph.D., Sathyabama Institute of Science and Technology for providing us with sufficient facilities.

We would like to express our sincere thanks and deep sense of gratitude to my supervisor Dr. A. Sivasangari, Associate Professor, School of Computing, Sathyabama Institute of Science and Technology for her valuable guidance, suggestions and constant encouragement which paved way for the successful completion of this project work.

\section{REFERENCES}

[1] Zhou B., et al (2015),"mCloud: A Context-aware Offloading Framework for Heterogeneous Mobile Cloud"e, IEEE Transactions on Services Computing, pp. 19391374.

[2] Wang C., et al (2016), “Automated Detection of Road Manhole and Sewer Well Covers from Mobile LiDAR Point Cloudse, IEEE Geoscience and Remote Sensing Letters, Vol. 11(9).

[3] Chen X (2015), "Decentralized computation offloading game for mobile cloud computing”, IEEE Transactions on Parallel and Distributed Systems, Vol. 26(4), pp. 974983.

[4] Cheng Z, et al (2015), "Just-in-time code offloading for wearable computingee, IEEE Transactions on Emerging Topics in Computing, Vol. 3(1), pp. 74-83.

[5] Xia Q, et al (2014), "Online algorithms for location-aware task offloading in two-tiered mobile cloud environments"e, IEEE/ACM International Conference on Utility and Cloud Computing, pp. 109-116.

[6] Shibata Y., et al (2015), “A Road Condition Monitoring System Using Various Sensor Data in Challenged Communication Network Environment", International Conference on Advanced Information Networking and Applications Workshops.

[7] Ito, K., et al (2015, "A Road Condition Sharing System Using Vehicle-to-Vehicle Communication in Various Communication Environment", In IEEE Complex, Intelligent, and Software Intensive Systems (CISIS) Ninth International Conference publishing, pp. 242-249.

[8] Milford, M.J. and Wyeth, G.F., (2012), ,Seq SLAM: Visual route-based navigation for sunny summer days and stormy winter nightse", In Robotics and Automation (ICRA), IEEE International Conference, pp. 1643-1649.

[9] Oniga F., and Nedevschi, S., (2007), "Road surface and obstacle detection based on elevation maps from dense stereo", IEEE Intelligent Transportation Systems Con ference, pp. 859-865. 
Deepa D, R. Vignesh, Sivasangari A, Suja Cherukullapurath Mana, B. Keerthi Samhitha and Jithina Jose

[10] Ishigaki Y., et al (2013), "Development of mobile radiation monitoring system utilizing smartphone and its field tests in Fukushimaee, IEEE Sensors Journal,Vol.3(10), pp.35203526.

[11] Anitha Ponraj, (2017), "Optimistic VM Placement in cloud data centers using queuing approach",Future Generation Computer Systems (Elsevier), Volume 93, April, pp. 338344.

[12] R. Vignesh, D. Deepa, P. Anitha, S. Divya and S. Roobini, (2020) "Dynamic Enforcement of Causal Consistency for a Geo-replicated Cloud Storage System", International Journal of Electrical Engineering and Technology, 11(3), pp. 181- 185.

[13] R. Vignesh, K.Mohana Prasad, (2019) "Cloud-Implementation of E-Healthcare Framework", International Journal of Recent Technology and Engineering (IJRTE) ISSN: 2277-3878, Volume-8 Issue-3, September

[14] Divya.S., R. Vignesh., Revathy, R. (2019)"A Distincitve Model to Classify Tumor Using Random Forest Classifier", Proceedings of the 3rd International Conference on Inventive Systems and Control, ICISC

[15] Vignesh Ramamoorthy, S. Divya, Suja Cherukullapurath Mana and B. Keerthi Samhitha," Examining and Sensing of Artificial Knee with Multi Sensors Networks", Journal of Advanced Research in Dynamical and Control Systems(JARDCS),10(4),115-120.

[16] Hamad Balhareth, (2018) Cloud Computing Strategy and Adoption in Higher Education: The Case of Saudi Arabia. International Journal of Information Technology \& Management Information System 9(1), pp. 30-38.

[17] S. Drissi, S. Benhadou and H. Medromi, (2017) An Autonomous Risk Assessment Model for Cloud Computing Based on Multi-agent System before and after the Cloud Adoption. International Journal of Computer Engineering \& Technology, 8(4), pp. 19-30

[18] R. Ramakrishnanand V. Mathivanan. (2015) An Criticism of Contemporary Cloud Computing Productions and Encounters. International Journal of Computer Engineering and Technology, 6(8), pp. 41-50.

[19] Suvendu Chandan Nayak, Sasmita Parida, (2013) An Approach for Secured Data Transmission at Client End in Cloud Computing, International Journal of Computer Engineering and Technology, 4(4), pp. 381-389.

[20] Bhavik Agrawal, (2013) Green Cloud Computing, International Journal of Electronics and Communication Engineering \& Technology, 4(7), pp. 239-243. 